\title{
Learning-dependent potentiation in the vibrissal motor cortex is closely related to the acquisition of conditioned whisker responses in behaving mice
}

\author{
Julieta Troncoso, ${ }^{1,2}$ Alejandro Múnera, 1,3 and José María Delgado-García ${ }^{1,4}$ \\ ${ }^{1}$ División de Neurociencias, Universidad Pablo de Olavide, 41013-Sevilla, Spain; ${ }^{2}$ Departamento de Biología, Facultad de \\ Ciencias, Universidad Nacional de Colombia, Bogotá, Distrito Central, Colombia; ${ }^{3}$ Departamento de Ciencias Fisiológicas, \\ Facultad de Medicina, Universidad Nacional de Colombia, Bogotá, Distrito Central, Colombia
}

\begin{abstract}
The role of the primary motor cortex in the acquisition of new motor skills was evaluated during classical conditioning of vibrissal protraction responses in behaving mice, using a trace paradigm. Conditioned stimulus (CS) presentation elicited a characteristic field potential in the vibrissal motor cortex, which was dependent on the synchronized firing of layer V pyramidal cells. CS-evoked and other event-related potentials were particular cases of a motor cortex oscillatory state related to the increased firing of pyramidal neurons and to vibrissal activities. Along conditioning sessions, but not during pseudoconditioning, CS-evoked field potentials and unitary pyramidal cell responses grew with a time-course similar to the percentage of vibrissal conditioned responses (CRs), and correlated significantly with CR parameters. High-frequency stimulation of barrel cortex afferents to the vibrissal motor cortex mimicked CS-related potentials growth, suggesting that the latter process was due to a learning-dependent potentiation of cortico-cortical synaptic inputs. This potentiation seemed to enhance the efficiency of cortical commands to whisker-pad intrinsic muscles, enabling the generation of acquired motor responses.
\end{abstract}

The primary motor cortex plays an essential role in the generation and control of voluntary movements. As such, it should subtend motor adaptations to varying environmental challenges and to changes in behavioral and motivational states. Motor cortex responses to these demands require a considerable range of plasticity in cortical functional properties. In fact, there are abundant reports in many species indicating substantial plastic changes in the primary motor cortex during motor learning, or in response to cortical lesions (Sanes and Donoghue 2000; Sanes 2003; Krakauer and Shadmehr 2006). Although it has been proposed that long-term potentiation (LTP) and depression (LTD) of synaptic activities (and/or intracortical processing changes) in the primary motor cortex underlie the acquisition of new motor skills, no definitive proof of these putative mechanisms has yet been provided (Sanes 2003).

In rodents, goal-directed vibrissal whisking enables tactile exploration of the immediate environment. Such active exploration requires a fine cortical control of the whisker-pad musculature, which makes it an interesting model to determine primary motor cortex plasticity. Recently, the presence of a monosynaptic projection from the primary motor cortex to facial motoneurons controlling vibrissal muscles has been demonstrated in rats (Grinevich et al. 2005). Furthermore, there is robust evidence indicating the reorganization of vibrissal motor cortex representations and of cortical cell firing properties in response to central and peripheral lesions of the nervous system (Donoghue et al. 1990; Sanes et al. 1992; Nudo and Milliken 1996; Toldi et al. 1996; Sanes and Donoghue 2000; Franchi 2002). This reorganization of vibrissal motor cortex maps appears to depend on the occurrence of long-term plastic changes in intrinsic horizontal cortical connections (Baranyi et al. 1991; Jacobs and Donoghue 1991; Hess and Donoghue 1994; Hess et al. 1996; Huntley 1997;

${ }^{4}$ Corresponding author.

E-mail jmdelgar@upo.es; fax +34-954-349375.

Article is online at http://www.learnmem.org/cgi/doi/10.1101//m.341807.
Sanes and Donoghue 2000; Hess 2003), and is critically modulated by vibrissal somatosensory inputs (Keller et al. 1996; Franchi 2001).

It is well documented that whisker deflection can be used as a conditioned stimulus (CS) using classical conditioning procedures (Siucinska and Kossut 2004; Galvez et al. 2006). Moreover, in a preceding report, we found that the classical conditioning of vibrissal protraction responses to a tone, used as a CS, in conscious mice could be a useful model to the study of learninginduced changes in the facial motor system (Troncoso et al. 2004). In the present experiments, we used a trace conditioning paradigm, in which the CS consisted of a binaural tone, whilst the unconditioned stimulus (US) was an electrical shock presented to the right whisker-pad. The time interval between the CS and US was $250 \mathrm{msec}$. Using this conditioning procedure, we have found a learning-dependent potentiation of field potentials evoked at the vibrissal motor cortex by CS presentations during the acquisition of vibrissal conditioned responses (CRs) in alert behaving mice. This field-potential potentiation was related to changes in layer V pyramidal cell firing in response to CS presentation, which in turn was directly related to CR generation. Current source density analysis indicated that the principal components of vibrissal motor cortex-evoked field potentials represented a recruitment of layer $\mathrm{V}$ pyramidal neurons, which was anteceded and triggered by cortico-cortical inputs. Finally, highfrequency stimulation (HFS) of cortico-cortical afferents to the vibrissal motor cortex induced a long-lasting growth in evoked field potentials. This last fact suggests that the learningdependent plastic changes described here could be due to the strengthening of cortico-cortical inputs carrying CS-related information to the vibrissal motor cortex by mechanisms that might be similar to LTP. Although the CRs reported here are apparently devoid of an obvious functional sense, the inherent plasticity of the sensorimotor system seems capable of constructing motor responses on the basis of temporal relationships of stimuli, regardless of their functional purpose (Troncoso et al. 2004). In 
A
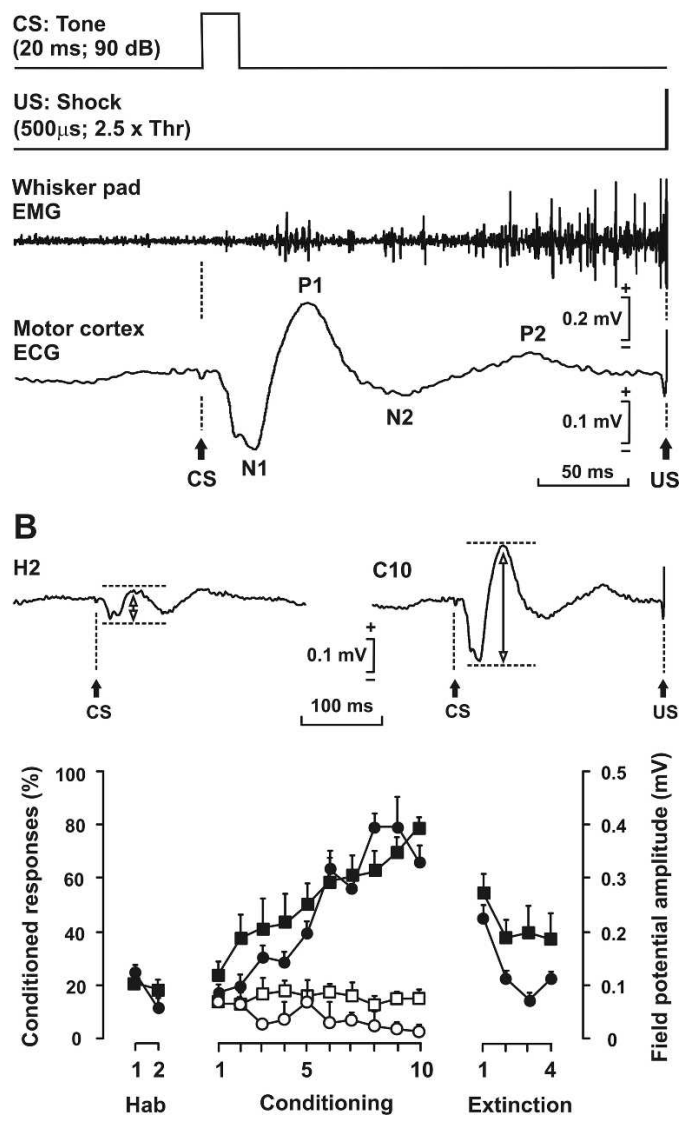

Figure 1. Changes in the amplitude of CS-evoked field potentials, at the vibrissal motor cortex, during classical conditioning of vibrissal protracting movements. (A) The two upper traces schematize the tone/ whisker-pad-shock trace conditioning paradigm, indicating the time (arrows and dashed lines) of CS (tone) and US (electrical shock) presentations. The EMG activity of the whisker-pad intrinsic musculature (middle trace) and CS-evoked field potential (lower trace) recorded in the contralateral vibrissal motor cortex during the tenth conditioning session are also shown. The successive components of CS-evoked potentials are named according to their polarity $(N, P)$ and order of appearance $(1,2)$. (B) (Upper row) Two examples of CS-evoked field potentials recorded during the second habituation ( $\mathrm{H} 2$, left) and the tenth conditioning (C10, right) sessions, illustrating N1-P1 (peak-to-peak) amplitude. (Lower panel) Comparison of the evolution of the percentage of CRs per session (squares) and N1-P1 amplitude (circles; in $\mathrm{mV}$ ) in both tone/whisker-padshock conditioned (black) and pseudoconditioned (white) animals. (Hab) Habituation.

summary, the present work contributes indirect evidence of the functional relationships between synaptic potentiation mechanisms present in the primary motor cortex and the acquisition of a simple motor task.

\section{Results}

\section{Classical conditioning of vibrissal protracting} movements and the evolution of CS-evoked field potentials in the vibrissal motor cortex

In agreement with a previous report (Troncoso et al. 2004), mice exposed to a trace (tone/whisker-pad-shock) conditioning paradigm acquired vibrissal CRs (Fig. 1A). As conditioning sessions went on, the percentage of CRs increased significantly $\left(F_{[9,90]}=84.3, P<0.001\right)$, reaching the learning criterion by the sixth training session (Fig. 1B, black squares). Concomitantly, the area under the curve of the rectified electromyographic (EMG) activity of whisker-pad muscles during the performance of CRs grew significantly, too $\left(F_{[9,90]}=4.283, P<0.01\right.$; Fig. $2 \mathrm{D}$, black squares). When fully developed, CRs were multiphasic and presented an in crescendo nature (Fig. 1A, whisker pad EMG). Contrastingly, in control pseudoconditioned animals, neither the CR percentage $\left(F_{[9,90]}=1.74, P=0.09\right.$; Fig. $1 \mathrm{~B}$, white squares $)$ nor the rectified EMG response of whisker-pad muscles during the CS-US interval $\left(F_{[9,90]}=1.89, P=0.06\right.$, Fig. $2 \mathrm{D}$, white squares $)$ changed significantly across conditioning sessions.

The CS used here (a binaural tone; $20 \mathrm{msec}, 2415 \mathrm{~Hz}, 90 \mathrm{~dB}$ ) evoked a tone-related field potential in the vibrissal motor cortex characterized by four stable components, easily identified from electrocorticographic (ECG) recordings (Fig. 1A, motor cortex ECG). These field potential components were named according to their polarity (N, negative; $\mathrm{P}$, positive) and order of appearance (1 and 2). For habituation sessions, field-potential components presented the following mean $( \pm$ S.D.) values: $N 1$, time to peak $=22.7 \pm 5.5 \mathrm{msec}$, peak amplitude $=54.8 \pm 10.4 \mu \mathrm{V} ; \mathrm{P} 1$,
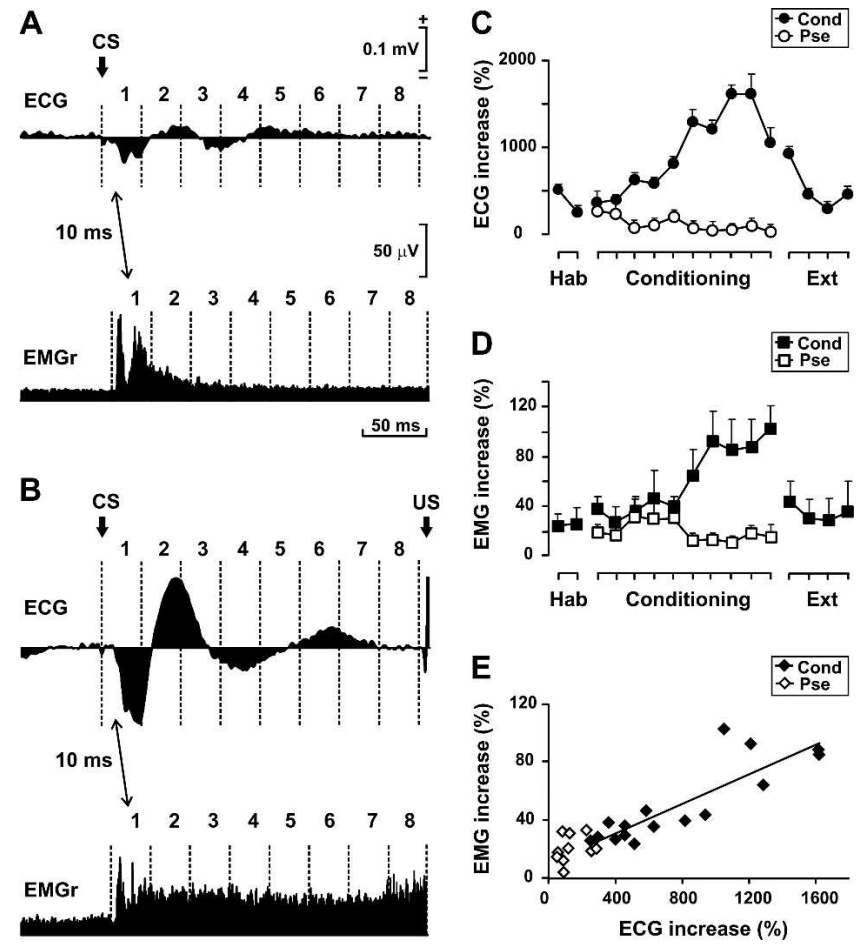

Figure 2. Learning-induced changes in CS-evoked field potentials were significantly correlated with the EMG activity of the contralateral whiskerpad muscles across conditioning. $(A, B)$ The two upper traces illustrate the area-under-the-curve of the CS-evoked field potential during a habituation $(A)$ and a late conditioning $(B)$ session. The two lower traces illustrate the area of the rectified and averaged EMG activity of the contralateral whisker-pad muscles, recorded during the same sessions. Each ECG and EMG averaged trace $(n=60)$ was divided into eight epochs of $30 \mathrm{msec}$ as indicated $(1-8)$. Note the delay of $10 \mathrm{msec}$ introduced into the EMG with respect to ECG epochs. (C) Evolution of the increase (in \%) of vibrissal motor cortex ECG area-under-the-curve modulus during the second epoch (30-60 msec) across training in conditioned (black circles) and pseudoconditioned (white circles) animals. (D) Evolution of the increase (in \%) in the rectified EMG area from contralateral whisker-pad muscles during the epochs encompassing CRs (40-240 msec) across training in conditioned (black squares) and pseudoconditioned (white squares) mice. $(E)$ Scatter plots illustrating the correlation between ECG and EMG modulus from both conditioned (black diamonds) and pseudoconditioned (white diamonds) animals. The best linear fit for conditioned data is also shown $(y=10.9+0.0508 x, r=0.85, P<0.001)$. (Cond) Conditioning, (Ext) extinction, (Hab) habituation, (Pse) pseudoconditioned. 
time to peak $=46.4 \pm 8.9 \mathrm{msec}$, peak amplitude $=26.8 \pm 12.1$ $\mu \mathrm{V} ; \mathrm{N} 2$, time to peak $=80.3 \pm 13.9 \mathrm{msec}$, peak amplitude $=40.0 \pm 11.5 \mu \mathrm{V}$; and $\mathrm{P} 2$, time to peak $=134 \pm 24 \mathrm{msec}$, peak amplitude $=30.6 \pm 9.1 \mu \mathrm{V}$. Across the successive conditioning sessions there was a significant increase in amplitude $\left(F_{[9,90]}=174.967, P<0.001\right.$, Fig. $1 \mathrm{~B}$, black circles $)$ and in the corresponding area-under-the-curve modulus $\left(F_{[9,90]}=18.051\right.$, $P<0.001$, Fig. 2A,B,C, black circles) of the vibrissal motor cortex CS-evoked field potential. This enhancement was dependent on associative learning, since it did not occur in pseudoconditioned mice (amplitude: $F_{[9,90]}=0.583, P=0.81$, Fig. $1 \mathrm{~B}$, white circles; area-under-the-curve modulus: $F_{[9,90]}=1.80, P=0.09$, Fig. 2C, white circles).

Interestingly, this growth in the amplitude of the vibrissal motor cortex CS-evoked field potential closely resembled the evolution of CR percentages across conditioning (Fig. 1B, black circles vs. black squares) and that of the rectified EMG activity from whisker-pad muscles (Fig. 2C, black circles vs. Fig. 2D, black squares). Moreover, taking into account data collected from every session, there was a significant linear correlation between the area-under-the-curve modulus of field potentials evoked at the vibrissal motor cortex by CS presentations and the rectified EMG activity recorded from whisker-pad muscles in conditioned, but not pseudoconditioned, mice (conditioned: $r=0.89, P<0.001$; pseudoconditioned: $r=-0.09, P=0.81$; Fig. 2E). During the first five conditioning sessions collected from conditioned animals, there is an apparent discrepancy between the increment in the percentage of CRs (Fig. 1B, black squares) and the corresponding increment in session average of CR amplitude (Fig. 2D, black squares). Such an apparent discrepancy was due to the fact that, although CRs occurred more frequently, they were rather shortlasting and presented a variable onset, which diluted the amplitude of individual CRs in a 60-trial average.

To further explore the possible relationships between vibrissal motor cortex activity and CR generation, both signals (CSevoked field potentials and EMG responses recorded from whisker-pad muscles during the CS-US interval) were divided into eight epochs of $30 \mathrm{msec}$ (Fig. 2A,B). Except for the first epoch, every motor cortex field-potential epoch had a good correlation with its corresponding whisker-pad musculature EMG epoch in conditioned $(r=0.56-0.80, P<0.01)$, but not in pseudoconditioned $(r=0.10-0.46, P>0.05)$, subjects. Among all vibrissal motor cortex CS-related potential epochs, the evolution of the 30- to 60-msec epoch across training (Fig. 2C) had the best correlation with the evolution of whisker-pad EMG activity during the whole CR period (40-240 msec after CS presentation; Fig. 2D) in conditioned, but not in pseudoconditioned, mice (conditioned: $r=0.85, P<0.001$; pseudoconditioned: $r=0.07, P=0.84$; Fig. 2E).

In order to check the proper location of recording electrodes implanted in the vibrissal motor cortex, once all the conditioning and pseudoconditioning sessions were finished, lowintensity $(<0.6-\mathrm{mA}), 50-\mu \mathrm{sec}$, square, catholic pulses were applied through the implanted electrode at a $0.1-\mathrm{Hz}$ frequency. In every subject, electrical stimulation of the vibrissal motor cortex elicited short-latency ( $\leq 5.2-\mathrm{msec})$ whisker-pad EMG responses (Fig. 3A). Such responses had two components: (1) $R 1_{\mathrm{cx}}$, time to peak $=9.88 \pm 0.27 \mathrm{msec}$, peak amplitude $=124.02 \pm 24.88 \mu \mathrm{V}$; and (2) $\mathrm{R} 2_{\mathrm{cx}}$, time to peak $=27.37 \pm 3.13 \mathrm{msec}$, peak amplitude $=37.93 \pm 7.14 \mu \mathrm{V}$ (Fig. 3A). When trains of five stimuli, at $50 \mathrm{~Hz}$, were administered in the vibrissal motor cortex, a characteristic pattern of whisker-pad EMG activity was observed: (1) there was a significant increase in the amplitude of the $\mathrm{R} 1_{\mathrm{cx}} \mathrm{com}$ ponent elicited by each successive pulse of the train $\left(F_{[4]}=19.33\right.$, $P<0.001$; Fig. $3 \mathrm{~B}$, dots); and (2) after the last $\mathrm{R} 1_{\mathrm{cx}}$ in response to the train, the $\mathrm{R} 2_{\mathrm{cx}}$ component (Fig. $3 \mathrm{~B}$, curved arrow) was fol-
A

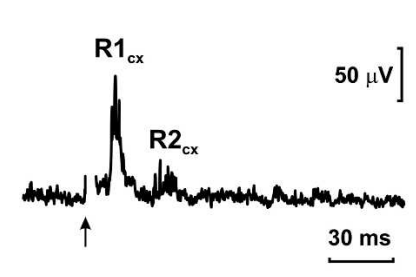

C
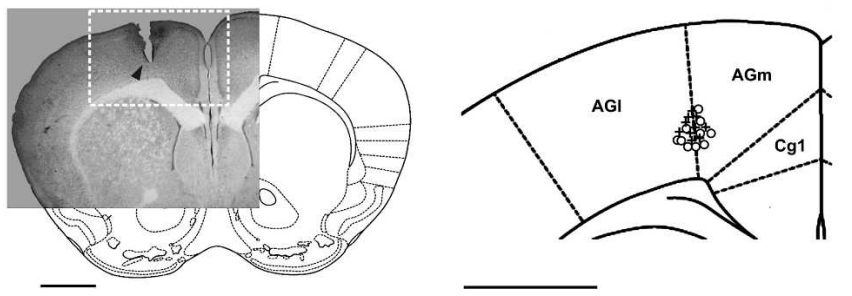

Figure 3. Evaluation of electrode placement by cortical stimulation and histological examination. $(A)$ Average of 30 whisker-pad rectified EMG responses to single $0.6-\mathrm{mA}, 50-\mu \mathrm{sec}$ long, square, catholic pulses administered through the recording electrode at the end of training. (Arrow) Beginning of the pulse. The early $\left(R 1_{c x}\right)$ and late $\left(R 2_{c x}\right)$ components of the whisker-pad response are indicated. Stimulus artifact has been removed. $(B)$ Average of 30 whisker-pad rectified EMG responses to trains of five 0.6-mA, 50- $\mu$ sec long, square, catholic pulses at a $50-\mathrm{Hz}$ frequency. (Arrows) Beginning of each pulse in the train. Stimuli artifacts have been removed. (Dots) $\mathrm{R} 1_{c x}$ components after each pulse in the train, (curved arrow) R2 component that occurred after the last pulse, (asterisk) protracted increase in whisker-pad EMG activity elicited by the train. (C) Microphotograph of a coronal section of a subject's brain overlapped onto the corresponding coronal diagram (AP: 0.98 from Bregma). (Arrowhead) Recording electrode placement, (white dotted line rectangle) area magnified in $D$. Calibration bar, $1 \mathrm{~mm}$. (D) Enlargement of the coronal diagram shown in $C$ illustrating the placement of the recording electrodes of all the conditioned (open circles) and pseudoconditioned (plus signs) subjects. (AGI) Lateral agranular cortex, (AGm) medial agranular cortex, (Cg1) cingulate cortex, area 1.

lowed by a sustained increase in whisker-pad EMG activity, which lasted for $\sim 200 \mathrm{msec}$ (Fig. 3B, asterisk). Histological examinations indicated that, in all conditioned and pseudoconditioned subjects, the recording electrodes were placed at layer $\mathrm{V}$, in the boundary between medial and lateral agranular cortices (Fig. 3C,D). Taken together, both cortical stimulation and histological examination indicated that the recording electrodes were implanted in the vibrissal primary motor cortex.

\section{Unit and population activity recorded in the vibrissal motor cortex in anesthetized and conscious mice}

In a first series of experiments, the electrical activity of layer $\mathrm{V}$ pyramidal neurons $(n=56)$ was recorded by inserting glass pipettes in the vibrissal motor cortex of anesthetized mice. These neurons, discriminated from high-pass filtered ECG by using a level window (Fig. 4A, middle trace), were characterized by a mean frequency of $<10$ spikes/sec, a typical bursting firing pattern (modal interspike interval: 4-5 msec; Fig. 4B, interspike time histogram), a duration of the spike negativity of $>1.5 \mathrm{msec}$, and a total spike duration of $>3 \mathrm{msec}$ (Fig. 4B, inset). Typically, layer $\mathrm{V}$ pyramidal neurons tended to fire during spontaneous and/or experimentally evoked field potential oscillations in the gamma band (30-40 Hz; Fig. 4A, upper trace) and were flanked by highfrequency oscillations (300-400 Hz; Fig. 4B, inset).

In another series of experiments, we recorded multi-unit 
A

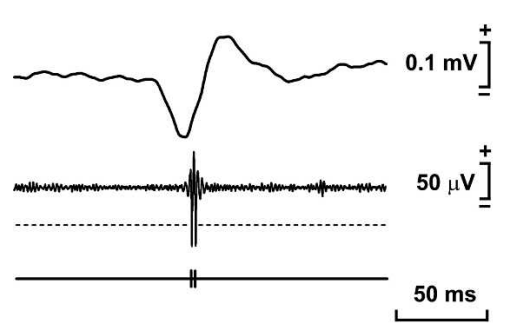

C

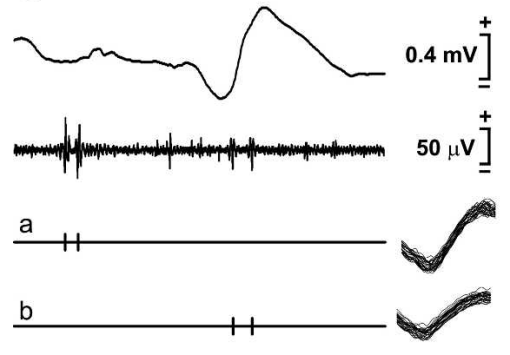

E

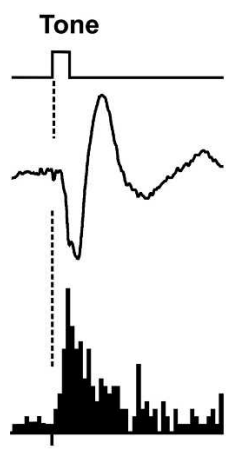

$\mathbf{F}$

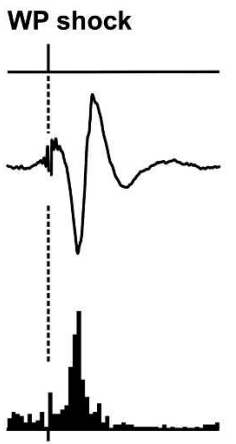

B

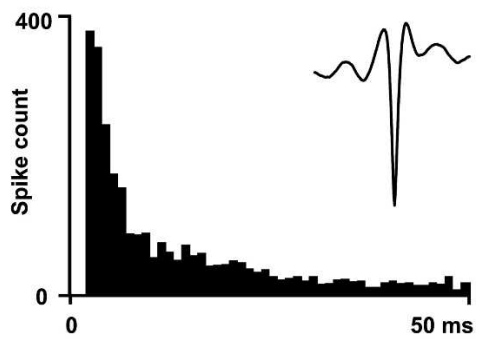

D

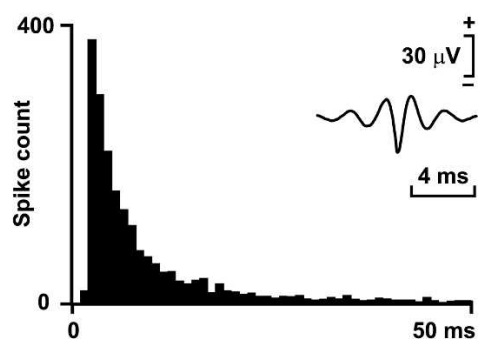

G

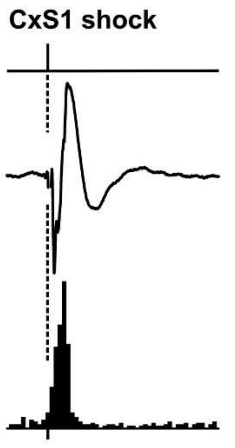

H

Spontaneous

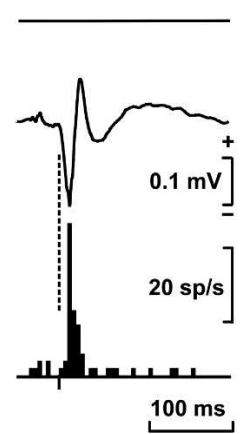

Figure 4. Spontaneous and experimentally evoked unit activity of layer $V$ pyramidal neurons and its relationship with field potentials recorded in the vibrissal motor cortex. (A) Representative 200-msec recording of spontaneous field potential activity (low-pass filtered ECG, upper trace) and simultaneous firing of a layer V pyramidal neuron (high-pass filtered ECG, middle trace) in the vibrissal motor cortex of an anaesthetized mouse. Spike discrimination using a level window is illustrated. The dotted line in middle trace represents the discriminating level. Spike occurrence is indicated by point events in lower trace. (B) Interspike time histogram and waveform (inset) of the neuron represented in $A$. (C) Representative 200-msec recording of spontaneous field potential activity (low-pass filtered ECG, upper trace) and simultaneous firing of multiple layer $\vee$ pyramidal neurons (high-pass filtered ECG, middle trace) in the vibrissal motor cortex of an alert and behaving mouse. Spike discrimination using a sorting routine based in amplitude, duration, and waveform parameters is illustrated. Occurrence of two sorted-out spikes $(a, b)$ is indicated by point events in the two lower traces. (Right-hand insets) Thirty overlapped traces of spikes that fitted the templates corresponding to spikes a and b. (D) Interspike time histogram and waveform (inset) of the neuron represented in C. Time calibration bar in $A$ is also valid for $C$. Time and amplitude calibration bars of the inset in $D$ are also valid for $B$. (E-H) Representative examples of field potentials recorded in the vibrissal motor cortex (middle row) and peri-event histograms from layer $V$ pyramidal neurons (lower row) evoked by a CS presentation ( $E$ ), electrical shocks presented to the contralateral whisker-pad ( $F$, WP shock), and to the ipsilateral somatosensory barrel cortex ( $G, \mathrm{CxS} 1$ shock), or generated spontaneously $(H)$. Note that, in every case, the maximum firing probability of layer $\mathrm{V}$ pyramidal cells occurred during the first negative component (N1) of field potential oscillations.

activity at the motor cortex in alert behaving mice prepared for classical conditioning (Fig. 4C, middle trace). This multi-unit activity was recorded from layer $\mathrm{V}$ pyramidal neurons $(n=283)$ by using wire electrodes. These neurons, which were discriminated from high-pass filtered ECG recordings by a Spike 2 sorting routine based in spike parameters (amplitude, duration, and wave-

form; Fig. 4C, lower two traces and insets), had firing patterns and waveforms akin to those recorded in anesthetized animals (Fig. 4, cf. B and D).

Layer $\mathrm{V}$ pyramidal neurons from the vibrissal motor cortex displayed a stereotyped bursting response to either acoustic or somatosensory stimuli (Fig. $4 \mathrm{E}-\mathrm{G}$, lower row). The discharge rate of layer $\mathrm{V}$ pyramidal neurons was found to be closely related with specific components of event-related field potentials recorded in the vibrissal motor cortex (Fig. $4 \mathrm{E}, \mathrm{F}, \mathrm{G}$, upper row). In conditioned mice, the unitary pyramidal cell responses to CS presentation were closely related to CS-evoked field potentials. Specifically, the firing of pyramidal neurons was maximal during the N1 peak and N1-P1 slope of the CS-related field potential (Fig. 4E). Vibrissal motor cortex population activity evoked by either contralateral whisker-pad electrical stimulation (Fig. 4F, upper trace) or ipsilateral barrel cortex electrical stimulation in anesthetized animals (Fig. 4G, upper trace) was found to have components similar in shape to those field potentials evoked in behaving mice by CS presentations, but with different latencies and durations. The amplitude and latency of these somatosensory-related field potentials were highly dependent on stimulus intensity (data not shown). In any case, the probability of layer $\mathrm{V}$ pyramidal neurons' firing in response to both kinds (whisker-pad or barrel cortex) of somatosensory stimulation was maximum during the N1 peak and the N1-P1 slope of the evoked potential (Fig. 4F,G, lower row).

During intervals between CS-US presentation trials, the population activity recorded at the vibrissal motor cortex presented spontaneous oscillations similar to the event-related field potentials evoked by CS presentations and by peripheral (whisker-pad) and central (barrel cortex) somatosensory stimulations. These spontaneous oscillations were recorded in the vibrissal motor cortex both in anesthetized (Fig. 4A, upper trace; Fig. $4 \mathrm{H}$, upper trace) and in alert behaving (Figs. 4C and 5A, upper trace) mice. Their occurrence was identified and marked by a pattern-recognition routine in order to trigger peristimulus time histograms and rectified EMG averages (Fig. 6A). During the N1 peak and the N1-P1 slope of these spontaneous oscillations, the firing rate of layer $\mathrm{V}$ pyramidal neurons reached maximum values (Fig. 4H). It was also noticed that, in coincidence with the N1 peak and N1-P1 slope components of these spontaneous oscillations of vibrissal motor cortex activities, the amplitude of the EMG activity of whisker-pad muscles rose steeply, reaching a significant level $(65.2 \pm 15.8 \mu \mathrm{V}$, on average; $P \leq 0.05)$ over base- 
A

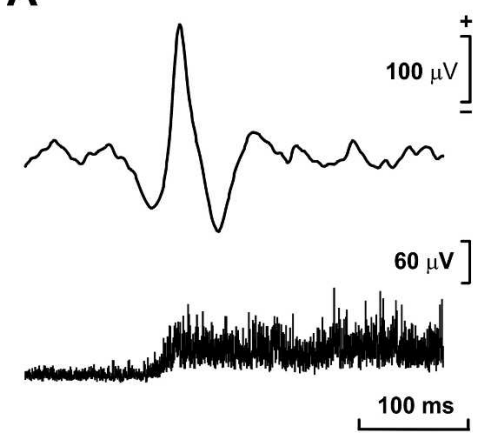

B

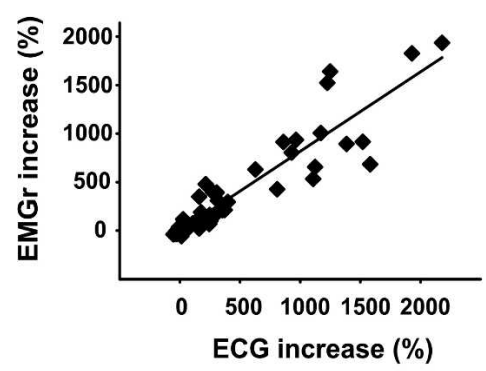

C

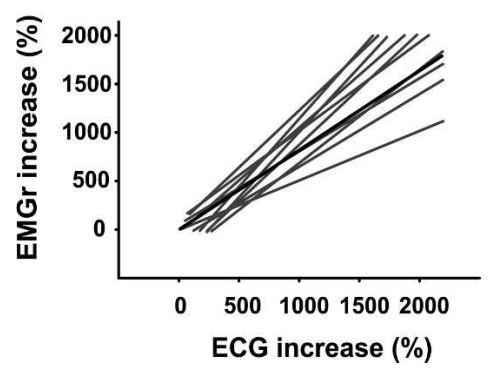

D

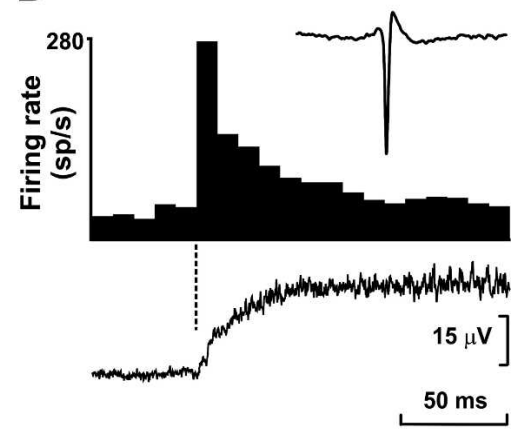

E

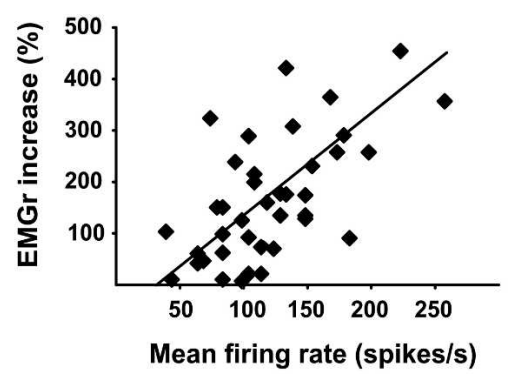

$\mathbf{F}$

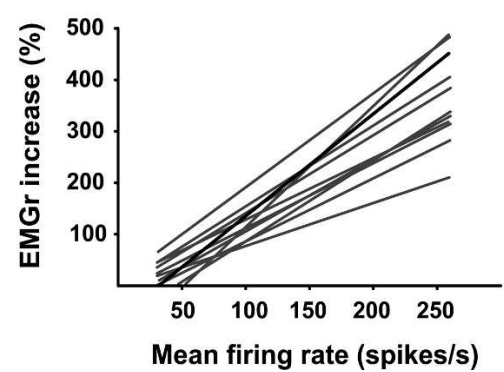

Figure 5. Vibrissal motor cortex event-related-like spontaneous population oscillations and layer $\mathrm{V}$ pyramidal neurons' unit firing elicited sustained increases in whisker-pad intrinsic musculature EMG activity. (A) Correlative averages $(n=50)$ of spontaneous field potential oscillations recorded at the vibrissal motor cortex (upper trace) and of the rectified and averaged EMG activity recorded at the contralateral whisker-pad intrinsic musculature (lower trace). (B) Scatter plot and best linear fit $(r=0.92, P<0.001)$ illustrating the correlation between spontaneous oscillations recorded in the vibrissal motor cortex and the increases in EMG activity recorded from the contralateral whisker-pad intrinsic musculature. Data were collected from every occurrence during a single recording session. (C) Best linear fits of the correlation between spontaneous oscillations recorded in the vibrissal motor cortex and the increases in EMG activity recorded from the contralateral whisker-pad intrinsic musculature during ten representative recording sessions of different subjects (gray lines). (Black line) Linear fit shown in $B$. (D) Burst start-triggered peri-event histogram (bin width $=10 \mathrm{msec}$ ) of a representative layer V pyramidal neuron (upper trace) and the rectified EMG average (lower trace) from whisker-pad muscles recorded during the intertrial intervals of a conditioning session. (Inset) Typical waveform of layer $\mathrm{V}$ pyramidal neuron action potential recorded from an alert behaving mouse (trace length: 40 msec, spike peak-to-peak amplitude: $1.24 \mathrm{mV})$. (E) Scatter plot and best linear fit $(r=0.68, P<0.001)$ illustrating the correlation between the mean firing frequency of a layer $V$ pyramidal neuron from the vibrissal motor cortex during the first $30 \mathrm{msec}$ of a burst and the (rectified) EMG activity of the contralateral whisker-pad intrinsic musculature during the intertrial intervals of a single conditioning session. $(F)$ Best linear fits of the correlation between mean firing frequency of a layer $\mathrm{V}$ pyramidal neuron from the vibrissal motor cortex during the first $30 \mathrm{msec}$ of a burst and the (rectified) EMG activity of the contralateral whisker-pad intrinsic musculature during the intertrial intervals of 10 representative recording sessions of different subjects (gray lines). (Black line) The linear fit shown in $E$.

line values, which persisted for hundreds of milliseconds $(378 \pm 116 \mathrm{msec})$ after the oscillation (Fig. $5 \mathrm{~A})$. Moreover, and as described for CS-evoked field potentials, there was a significant correlation between the area-under-the-curve modulus of the spontaneous oscillations recorded from the vibrissal motor cor- tex and the corresponding increase in the EMG activity of the contralateral whisker-pad muscles, particularly during the period of time including the N1 peak and the N1-P1 slope $(r=0.79-0.94$, $P<0.001$; Fig. 5B,C).

In alert behaving mice, as well as in anesthetized ones, layer $\mathrm{V}$ pyramidal neurons recorded at the vibrissal motor cortex fired characteristically in bursts (Fig. 6A). In behaving mice, bursts lasted for $50-70 \mathrm{msec}$. Following ( $\sim \mathrm{msec})$ the beginning of a burst, there was a slight increase in the amplitude of whisker-pad EMG activity $(12.8 \pm 6.8 \mu \mathrm{V}$, on average), which persisted for tens of milliseconds (97 \pm 26 msec; Fig. 5D). This increase in the EMG activity of whiskerpad muscles was linearly correlated with the mean firing frequency of pyramidal cells during the first $30 \mathrm{msec}$ of the burst $(r=0.58-0.70, P<0.001$; Fig. 5E,F).

Since vibrissal motor cortex layer $\mathrm{V}$ pyramidal neurons' firing was enhanced during field potential oscillations, we hypothesized that distinct oscillatory states in this cortex would lead to different vibrissal motor system outputs, expressed as varying degrees of whiskerpad muscular activity. Therefore, we further explored such a relationship during the time intervals between CS-US presentation trials. In fact, the presence of two distinct functional states in the ECG and unit activity of the vibrissal motor cortex was readily observed. One functional state was characterized by a predominant theta-band (3.1-9 Hz) population oscillation $(73.4 \% \pm 8.2 \%$ of the whole power spectral density was concentrated in the theta band, with a dominant frequency of $\sim 5 \mathrm{~Hz}$ ), and sparse or no layer $\mathrm{V}$ pyramidal neuron firing (Fig. 6A, left side; Fig. 6B). This functional state was associated with a noticeable absence of EMG activity from the whisker-pad intrinsic musculature (Fig. 6A, left side, lower trace). In the second functional state, layer $\mathrm{V}$ pyramidal neurons presented recurrent bursts, and the oscillation present in ECG recordings had higher amplitude and absolute power spectral density ( 10 - to 12 -fold increase in relative power spectral density; Fig. 6A, right side, and Fig. 6C). In addition, during this second functional state, population oscillations had a prominent frequency shift toward alpha (four- to fivefold increase), beta (two- to threefold increase), and gamma (two- to threefold increase) bands (Fig. 6B,C). This second functional state was accompanied by the presence of repetitive bursts of activity in the EMG records from whisker-pad muscles (Fig. 6B, right side, lower trace). These two discrete functional states recorded from the vibrissal motor cortex were also observed in anesthetized mice, but with a drastic decline in theta 
A

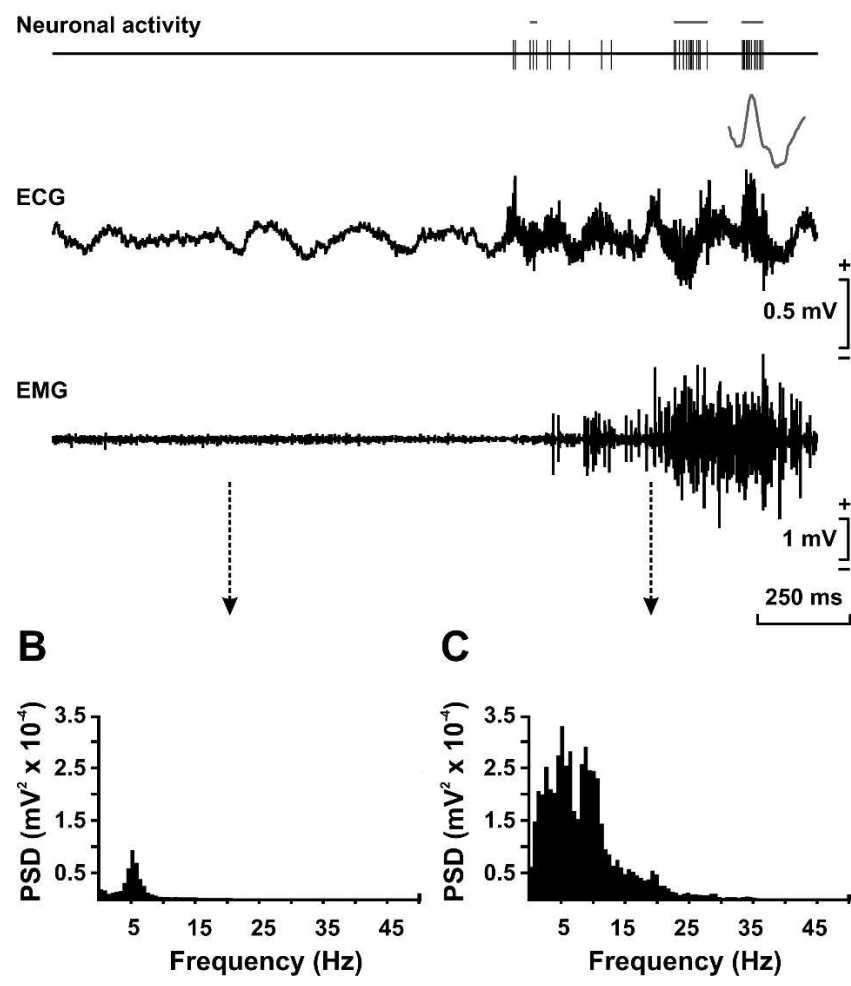

Figure 6. The state of activity in the whisker-pad intrinsic musculature was closely related with two distinct functional states of the contralateral vibrissal motor cortex. (A) A two-second simultaneous recording of the spontaneous unit (upper trace) and ECG (middle trace) activities of the vibrissal motor cortex, and of the EMG activity of the contralateral whisker-pad muscles (lower trace). The sample record encompasses a transition (dashed line) between the two cortical functional states. The occurrence of spontaneous bursts of a discriminated layer $\mathrm{V}$ pyramidal neuron is indicated just above the upper trace (gray bars). An evoked-potentiallike spontaneous field potential oscillation identified by the patterrecognition routine is also indicated above the middle trace (gray waveform; note the close relationship with a burst of the discriminated pyramidal neuron). ( $B, C$ ) Power spectrum density (PSD) histograms (in $\mathrm{mV}^{2}$ ) of the vibrissal motor cortex population activity (ECG) during the two functional states illustrated in $A$. The two descending arrows indicate the correspondence between the spectral power and each cortical oscillatory state.

band power and no spontaneous activity from whisker-pad muscles (data not shown).

\section{Current source density analysis of the vibrissal motor cortex}

Since vibrissal motor cortex field potentials evoked by stimuli of different modalities and spontaneous oscillatory events were similar in shape, we hypothesized that they represent a stereotypical activity pattern. Such activity pattern was probably dependent on the functional organization of intracortical circuitry and would be engaged in the generation of cortical commands to facial motoneurons. Then, in order to unveil the events underlying the generation of such motor commands, an attempt was made to determine the laminar distribution of currents shaping vibrissal motor cortex event-related potentials. For this, field potentials evoked by electric shocks presented to the whisker-pad were recorded in the vibrissal motor cortex, in steps of $100 \mu \mathrm{m}$, from 0.1 to $1 \mathrm{~mm}$ from the pial surface, in anesthetized animals (Fig. 7A,B). The one-dimensional approach for current-source density analysis (Freeman and Nicholson 1975) applied to these data showed the laminar and temporal distribution of current sinks and sources in the vibrissal motor cortex during somatosensory-evoked field potentials (Fig. 7C). During a slight positive field potential deflection preceding the N1 component, two prominent sinks were observed: (1) a sink propagating from upper layer III to layer II, which occurred $\sim 6-8$ msec after whiskerpad shock; and (2) successive sinks confined to layer IV, which occurred 10-25 msec after stimulus presentation. During the N1 and N1-P1 slope, starting 20 msec after whisker-pad stimulation, a profound and fast sink was observed in deep portions of layer $\mathrm{V}$, which propagated along the following $20 \mathrm{msec}$ toward more superficial portions of layer $\mathrm{V}$ and to deep portions of layer III (Fig. 7C). Immediately afterward, during the late P1 component, two simultaneous sinks occurred in layer IV, and in upper layer III and layer II. Finally, during the N2 and P2 components, disperse and shallow sources and sinks were observed.

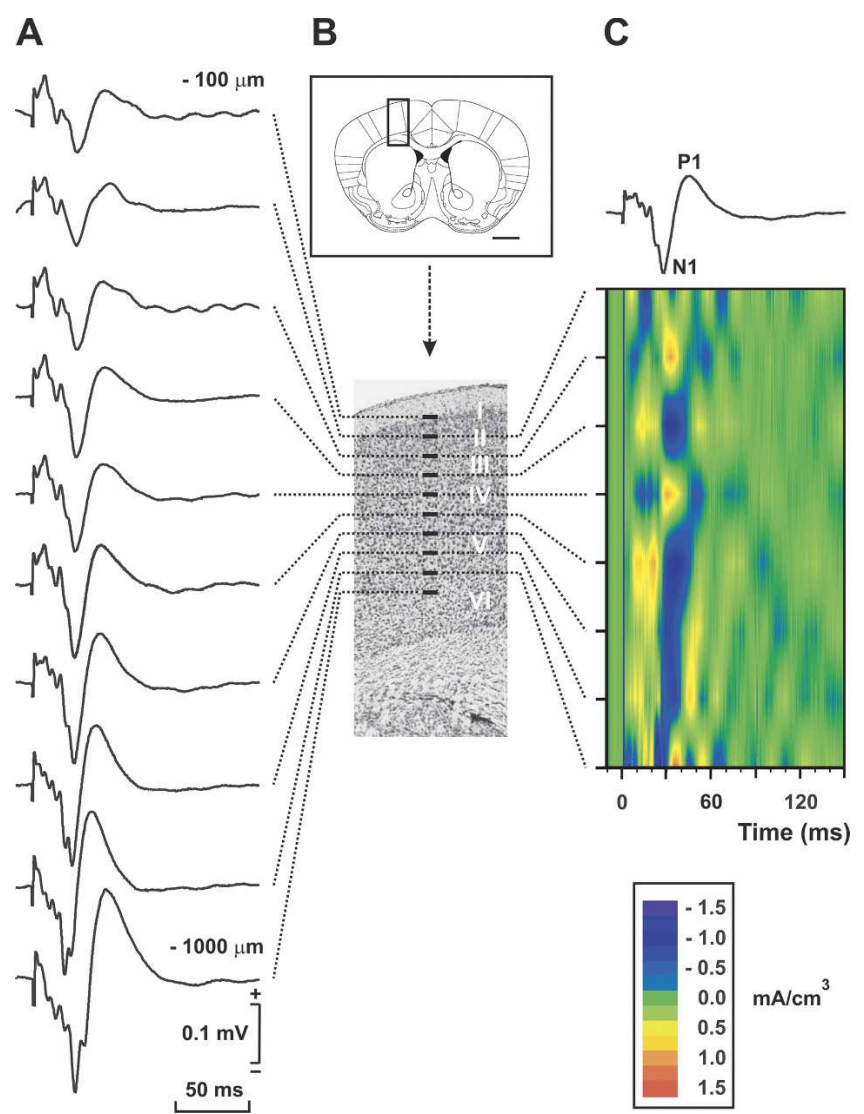

Figure 7. Current source density analysis unveiled the laminar determinants of primary motor cortex event-related field potentials. $(A)$ Depth profile of the vibrissal motor cortex field potentials evoked by the electrical stimulation of the contralateral whisker-pad. Population activity was recorded at intervals of $100 \mu \mathrm{m}$ between 0.1 and $1 \mathrm{~mm}$ of depth from the pial surface. (B) Light microphotograph of the medial-to-lateral transition of the left agranular cortex, illustrating the recording cortical layers and recording sites. (Inset) Diagram of a coronal section of mouse brain, indicating the area magnified in the microphotograph. Scale bar, $1 \mathrm{~mm}$. (C) Contour plot illustrating the spatial $(\mu \mathrm{m})$ and temporal (msec) distribution of current sources (red) and sinks (blue) in the vibrissal motor cortex during the evolution of whisker-pad-evoked field potentials (in $\mathrm{mA} / \mathrm{cm}^{3}$ ). A trace of an evoked field potential recorded at $700 \mu \mathrm{m}$ from the pial surface is displayed above to illustrate the relationship of the source-sink distribution with the successive field potential components. Note the sink beginning in the deep layer $\mathrm{V}$ and propagating upwards, and its relationship with the N1 peak and N1-P1 slope of the whiskerpad-evoked field potential. 
Long-term potentiation of the vibrissal motor cortex

We also attempted to determine the possibility of evoking LTPlike processes in the vibrissal motor cortex by HFS stimulation of the ipsilateral somatosensory barrel cortex. As illustrated in Figure 8 , single pulses applied to the barrel cortex at a rate of $0.1 \mathrm{~Hz}$ in anesthetized mice evoked a characteristic field potential in the vibrissal motor cortex (Figs. 4C and 8A). In this situation, an HFS protocol presented to the somatosensory barrel cortex induced a significant $(P \leq 0.01$, for values collected during the $60 \mathrm{~min}$ following HFS) increase in the N1-P1 peak amplitude of the field potential evoked at the vibrissal motor cortex by single pulses presented at the barrel cortex (Fig. 8C).

\section{Discussion}

Results collected from the present study strongly suggest the presence of an associative learning-dependent potentiation of field potentials evoked in the vibrissal motor cortex by CS presentation, during classical conditioning of whisker-protracting responses in alert behaving mice. This learning-dependent potentiation, which followed a time-course similar to the increases in both CR percentages and whisker-pad EMG amplitude during motor learning acquisition, was related to an increase in the fir-
A

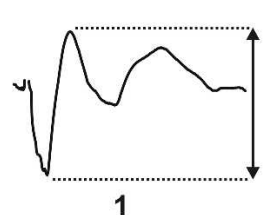

C

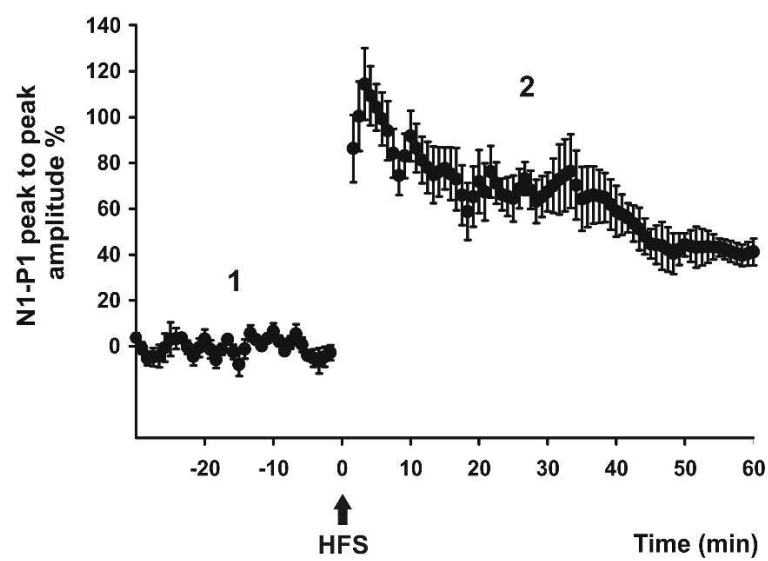

B

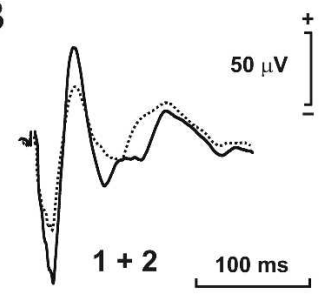

Time $(\min )$
Figure 8. High-frequency stimulation (HFS) of cortico-cortical inputs induced a long-term increase in the amplitude of field potentials evoked in the vibrissal motor cortex by the electrical stimulation of the ipsilateral somatosensory barrel cortex. $(A)$ Characteristic waveform of field potentials evoked in the vibrissal motor cortex by the electrical stimulation of the ipsilateral somatosensory barrel cortex. The N1-P1 peak-to-peak amplitude measurement (in $\mathrm{mV}$ ) is illustrated. Sample record obtained during baseline (1). (B) Comparison of field potentials $(1+2)$ recorded in the vibrissal motor cortex before (dotted line, 1) and after (solid line, 2) HFS of the somatosensory barrel cortex. Note the increase in all the components of the evoked field potential. (C) Average time evolution of field potentials (N1-P1 peak-to-peak amplitude, in \%) evoked in the vibrissal motor cortex during all HFS experiments. Note that the amplitude of the field potentials evoked in the vibrissal motor cortex by single pulses presented (at $0.1 \mathrm{~Hz}$ ) to the ipsilateral somatosensory barrel cortex was potentiated by the HFS, and that this potentiation remained significant after $60 \min \left(41.15 \pm 5.8 \% ; t_{[184]}=-25.56, P<0.001\right)$. ing rate of layer $\mathrm{V}$ pyramidal cells in response to CS presentations and, thus, to the generation of vibrissal CRs.

Field potentials evoked in the vibrissal motor cortex by CS presentations were locally generated and not due to volumeconduction from the auditory cortex, since their amplitudes were not significantly different from those of peripherally and centrally evoked somatosensory potentials. Moreover, the N1-P1 slope of those CS-evoked field potentials was directly related with the peak firing rate of layer $\mathrm{V}$ pyramidal neurons, also in response to CS presentations. Since stimuli of different sensory modality evoked oscillatory patterns in the vibrissal motor cortex that were also observed spontaneously, even in anaesthetized animals, we inferred that such patterns reflect the activity of intrinsic cortical circuitries independently of the stimulus modality. To study the dynamics of the vibrissal motor cortex circuitry, and following a previous description in rats (Ahrens and Kleinfeld 2004), we successfully applied current source density analysis to the mouse motor cortex. In fact, current source density analysis of somatosensory-evoked potentials allowed us to dissect out the laminar determinants of event-related and spontaneous fieldpotential oscillations. A positive field-potential deflection before the beginning of the N1 component was related with sinks in layers II, III, and IV. Those sinks could represent, respectively, excitatory cortico-cortical inputs from the ipsilateral barrel cortex (Izraeli and Porter 1995), and excitatory thalamo-cortical inputs from posteromedial and ventrolateral nuclei (Donoghue et al. 1979; Donoghue and Parham 1983; Miyashita et al. 1994; Diamond 1995; Deschênes et al. 1998; Thomson and Bannister 2003). The N1 and N1-P1 slope occurred simultaneously with a sink originated in deep portions of layer $\mathrm{V}$ and propagated to upper portions of layer V and to layer III. Such events could be the result of excitatory synaptic activity from layer $V$ pyramidal neuron recurrent axonal branches (Mountcastle 1997; Thomson and Bannister 2003). The P1 descending slope coincides temporally with sinks in layer IV, and in upper portions of layer III and in layer II, which could represent excitatory inputs from deep layer III to inhibitory interneurons of layers II, III, and IV (Mountcastle 1997; Thomson and Bannister 2003). Then, the major components of vibrissal motor cortex-evoked potentials seemed to depend on the ordered activation of intrinsic cortical circuits triggered by synaptic inputs carrying stimulus information.

Most studies on primary motor cortex learning-related plasticity have shown changes in the size of cortical representations, presumably due to long-term modifications in the strength of horizontal intracortical synaptic connections (Baranyi et al. 1991; Jacobs and Donoghue 1991; Hess and Donoghue 1994; Hess et al. 1996; Huntley 1997; Sanes and Donoghue 2000; Hess 2003; Hayashi et al. 2005). In this regard, we are describing here, for the first time, a progressive increase of CS-evoked field potentials in the vibrissal motor cortex during the acquisition of a new motor act-namely, a classically conditioned whiskerprotraction response. As current source density analysis suggests, the activation of cortico-cortical excitatory synaptic inputs from the ipsilateral somatosensory barrel cortex antecedes the generation of the main components of evoked field potentials in the vibrissal motor cortex. An LTP-inducing treatment applied to this synaptic pathway resulted in an increase in the amplitude of the whole somatosensory-evoked field potential, which has been shown to depend on intracortical circuitry. This fact suggests that the learning-dependent potentiation of CS-evoked field potentials reported here could be dependent on a slow, cumulative LTP-like plastic change in the strength of cortico-cortical synaptic inputs to the vibrissal motor cortex arriving from secondary auditory cortex areas. Learning-dependent potentiation, however, was greater than HFS-induced potentiation of event-related 
field potential, which could be due to the discrete but repetitive character of behavioral conditioning (Frey et al. 1995).

Current flow in the vibrissal motor cortex of the rat has been found to be phase-locked with the EMG activity of whisker-pad intrinsic muscles during rhythmic whisker exploratory movements (Ahrens and Kleinfeld 2004). In the present work, as previously reported by Friedman et al. (2006), we found that vibrissal motor cortex field potential oscillation increased significantly prior to the onset of a whisking epoch, persisted while the whisking lasted, and ended prior to its termination. Additionally, during such oscillatory episodes, layer $\mathrm{V}$ pyramidal cells increased their firing frequency. Conversely, when low-amplitude and lowfrequency oscillations occurred in the vibrissal motor cortex, the firing frequency of layer $\mathrm{V}$ pyramidal neurons decreased, and no whisker-pad muscular activity was observed. Along the state of increased oscillations, events with a waveform similar to evoked potentials and associated with increased firing of pyramidal cells were observed. During spontaneous oscillations and evoked potentials, both population and unit activity recorded in layer $\mathrm{V}$ of the vibrissal motor cortex were found to be positively correlated with the EMG activity of the contralateral whisker-pad intrinsic musculature. These facts suggest that event-related potentials could be thought of as particular cases, induced by sensory information, of the enhanced oscillatory state of the vibrissal motor cortex. Moreover, it has been shown that the typical waveforms of event-related field potentials recorded in the vibrissal motor cortex depend on a series of specific excitatory events that recruit and shape layer $\mathrm{V}$ pyramidal neurons firing in response to sensory stimulation. That is, cortico-cortical and thalamocortical excitatory inputs to the vibrissal motor cortex precede and induce the activation of layer $\mathrm{V}$ pyramidal neurons, which in turn recruit other layer $\mathrm{V}$ pyramidal neurons through excitatory retrograde axonal collaterals. The recruitment of neighboring layer $\mathrm{V}$ pyramidal neurons manifests itself through $\mathrm{N} 1$ peak and N1/P1 slope components of event-evoked field potentials, and would explain the occurrence of a maximum in layer $\mathrm{V}$ pyramidal cells firing probability during such components. These results allow us to suggest that cortical functional states depend on the intrinsic properties of cortical circuits and, since they appeared also in anaesthetized animals, that these functional states are not directly dependent on the level of alertness or on the presence of specific stimuli of different sensory modalities.

According to the present results, the increase in firing rate of layer $\mathrm{V}$ pyramidal neurons precedes and is significantly correlated with the increased EMG activity of the whisker-pad intrinsic musculature. In fact, a single pyramidal neuron's burst is correlated with a significant increase in the EMG activity of whiskerpad intrinsic muscles. This increase characteristically occurred with a short latency $(\sim 5 \mathrm{msec})$ and persisted for tens of milliseconds. Interestingly, after a few conditioning sessions, the response of layer $\mathrm{V}$ pyramidal neurons from the vibrissal motor cortex to CS presentations was a 50- to 60-msec burst of action potentials, which was followed, with a short latency, by a significant and long-lasting increase in the amplitude of the EMG activity of the whisker-pad intrinsic musculature. It has recently been demonstrated that, in rodents, vibrissal motor cortex layer $\mathrm{V}$ pyramidal neurons project monosynaptically to facial motoneurons innervating whisker-pad intrinsic muscles (Grinevich et al. 2005). Such data suggest a direct cortical (motor) control of specific vibrissal movements. In this regard, we are reporting here the presence of a vibrissal motor cortex oscillatory state that recruits layer $\mathrm{V}$ pyramidal neurons' firing and, therefore, allows a direct cortical control of spontaneous whisker responses. Thus, the plastic changes observed in the amplitude of CS-evoked field potentials probably represent an increase in the strength of motor commands directed at generating a conditioned (i.e., ac- quired) response from the whisker-pad intrinsic musculature. Before training, and during the very first conditioning sessions, the strength of cortical motor commands was not strong enough to generate consistent responses to CS (neutral tone) presentations. However, along the classical conditioning of vibrissal protraction, consistent CS-US pairing induced the necessary and sufficient plastic changes in cortico-cortical synaptic inputs to the vibrissal motor cortex to enhance CS-evoked field potentials and the firing of layer $\mathrm{V}$ pyramidal neurons. These associative learning-dependent changes, therefore, efficiently increased motor cortex commands, and allowed the vibrissal motor system output to change from short-lasting and variable onset CRs (in whose generation brain-stem circuits would predominate), as seen at the beginning of conditioning, toward the generation of sustained and growing whisker-pad CRs (in whose generation vibrissal motor cortex commands would predominate).

\section{Materials and Methods}

\section{Subjects}

Experiments were carried out in 40 adult male Swiss-Webster mice, weighing 35-40 g, obtained from an official supplier (University of Granada Animal House). Before surgery, animals were housed in separate cages (10 per cage). Mice were kept on a 12-h light/12-h dark cycle with constant ambient temperature $\left(21^{\circ} \mathrm{C} \pm 1^{\circ} \mathrm{C}\right)$ and humidity $(50 \% \pm 7 \%)$. Food and water were available ad libitum. Electrophysiological and behavioral studies were carried out following the guidelines of the European Union Council (86/609/EU) and Spanish regulations (BOE 252/34367$91,2005)$ for the use of laboratory animals in acute and chronic experiments. Experiments were also approved by the University Ethical Committee for animal care and handling.

\section{Surgery}

All surgical procedures were performed under ketamine (100 mg/ $\mathrm{kg}$, i.p.) and xylazine $(10 \mathrm{mg} / \mathrm{kg}$, i.p.) anesthesia. Animals prepared for chronic recordings during conditioning $(n=20)$ were implanted with (1) bipolar recording electrodes in the right whisker-pad, (2) bipolar stimulating electrodes near the emergence of the right infraorbitary branch of the trigeminal nerve, and (3) a monopolar recording electrode aimed at the left vibrissal motor cortex. The stereotaxic coordinates from Bregma were the following: A-P $+1 \mathrm{~mm}$; L, $1 \mathrm{~mm}$; and D, $0.7 \mathrm{~mm}$ (Paxinos and Franklin 2001). Peripheral electrodes were made with $50-\mu \mathrm{m}$, Tefloncoated, annealed stainless steel wire (A-M Systems), whilst intracranial electrodes were made with $25-\mu \mathrm{m}$, polyimide-coated, tungsten wire (A-M Systems). An eight-pin socket, to which the wire terminals were soldered, was cemented to the skull. One week was allowed for full recovery from surgery.

Animals prepared for acute recordings $(n=20)$ were implanted with (1) bipolar stimulating electrodes near the emergence of the right infraorbitary nerve, and (2) bipolar stimulating electrodes directed at the left somatosensory barrel cortex. The stereotaxic coordinates from Bregma were A-P, $-1 \mathrm{~mm} ; \mathrm{L}, 2.5$ $\mathrm{mm}$; D, $1.2 \mathrm{~mm}$ (Paxinos and Franklin 2001). These electrodes were made with the above-mentioned stainless steel wire (A-M Systems). An additional hole was drilled in the skull at the stereotaxic coordinates of the left vibrissal motor cortex $(\mathrm{A}-\mathrm{P},+1$ $\mathrm{mm}$; L, $1 \mathrm{~mm}$ ) for field and unit recordings.

\section{Behavioral training}

Vibrissal protraction conditioning ( $n=10$ animals) was achieved using a tone/whisker-pad-shock trace conditioning paradigm. In this paradigm, the CS consisted of a binaural tone $(20 \mathrm{msec}, 2415$ $\mathrm{Hz}, 90 \mathrm{~dB}$ ), whilst the US was a $500-\mu \mathrm{sec}$ electrical shock presented to the right whisker-pad with a $2.5 \times$ threshold intensity (the intensity necessary to elicit reflex vibrissal responses $50 \%$ of the time, always $<800 \mu \mathrm{A}$ ). The time interval between CS and US was $250 \mathrm{msec}$. Each conditioned animal underwent a total of 16 sessions (one per day): two habituation (CS-only trials), 10 con- 
ditioning (paired CS-US trials), and four extinction (CS-only trials). Each session consisted of 60 stimulus presentations (trials). A control group $(n=10)$ underwent 10 pseudoconditioning sessions. During each pseudoconditioning session, 60 CS-US pairs with pseudorandom interstimuli interval were presented: for each CS-US pair it was assigned a pseudorandom interstimuli interval varying from -2 sec (i.e., US anteceding CS by 2 sec) to $2 \mathrm{sec}$ (i.e., CS anteceding US by $2 \mathrm{sec}$ ).

During each recording session, the animal was gently introduced into a cylindrical $(10 \times 5-\mathrm{cm})$ plastic box, and its socket was connected to the recording and stimulating systems. The stimulus dispensers (either a loudspeaker or an isolation unit) were commanded by a computer-controlled pulse generator (EMDPP, Cibertec). Further details of these experimental procedures have been detailed elsewhere (Troncoso et al. 2004).

\section{Stimulation in anesthetized animals}

Whisker-pad electrical stimuli were 0.8- to 6-mA, 50-usec, square, cathodic pulses delivered every $10 \mathrm{sec}$ in the right infraorbitary region. Somatosensory cortex electrical stimuli were 0.2- to 1.0$\mathrm{mA}, 50-\mu \mathrm{sec}$, square, cathodic pulses delivered every $10 \mathrm{sec}$ in layer $\mathrm{V}$ of the left barrel cortex. In order to assess the effects of HFS of cortico-cortical projections from the barrel cortex to the vibrissal motor cortex $(n=10), 10$ series of pulse trains were administered at 2-min intervals. In each series, six pulse trains were administered at 10 -sec intervals. In each train, 10 stimuli were administered at intervals of $10 \mathrm{msec}$. Each stimulus consisted of a 1.0-mA, 50- $\mu \mathrm{sec}$, square, cathodic pulse delivered in layer $\mathrm{V}$ of the left barrel cortex. During periods of $30 \mathrm{~min}$ before and $60 \mathrm{~min}$ after HFS, stimulus intensity and frequency were set at $0.6 \mathrm{~mA}$ and $0.1 \mathrm{~Hz}$, respectively.

\section{Recording procedures}

In chronic (alert behaving) mice, the EMG signal was magnified $(\times 1000)$ and filtered $(10 \mathrm{~Hz}$ to $10 \mathrm{kHz})$ using an AC-coupled differential amplifier (P511, Grass-Telefactor). Field potentials and multi-unit activity recorded from the vibrissal motor cortex were magnified $(\times 5000)$ and filtered $(0.3 \mathrm{~Hz}$ to $10 \mathrm{kHz})$ using an AC-coupled amplifier (P511, Grass-Telefactor).

In acute (anesthetized) mice, a glass micropipette (4-6 M $\Omega$ ) filled with $3 \mathrm{M} \mathrm{NaCl}$ was inserted in the vibrissal motor cortex. Field potentials and unit activity elicited by either right whiskerpad or left barrel cortex electrical stimulation were recorded $0.7-$ $0.8 \mathrm{~mm}$ from the brain surface. In order to make a current source density analysis of the somatosensory (whisker-pad) stimulationrelated potential $(n=10)$, field potentials evoked at the vibrissal motor cortex by whisker-pad stimulation were recorded at 10 different depth-points $100 \mu \mathrm{m}$ apart from each other (100-1000 $\mu \mathrm{m}$ from the pial surface). Vibrissal motor cortex population and unit activities were magnified $(\times 100)$ using a DC-coupled preamplifier (NEX-1, Biomedical Engineering), and then filtered (0.3 $\mathrm{Hz}$ to $10 \mathrm{kHz})$ and magnified $(\times 100)$ with an AC-coupled amplifier (Biomedical Engineering).

\section{Histology}

Once each experiment was finished, mice were deeply reanesthetized (sodium pentobarbital, $50 \mathrm{mg} / \mathrm{kg}$ ), and perfused transcardially with saline and 4\% phosphate-buffered paraformaldehyde. Selected sections (50- $\mu \mathrm{m}$ thick) including vibrissal motor and/or somatosensory barrel cortices were mounted on gelatinized glass slides and stained with $0.1 \%$ toluidine blue to determine the location of intracranial recording and stimulating electrodes.

\section{Data processing and analysis}

During conditioning, EMG, ECG, and stimulus command signals were digitized on-line using an analog/digital converter (CED 1401-Plus, Cambridge Electronic Design) with a 16-bit vertical resolution and a sampling frequency of 10,25 , and $1 \mathrm{kHz}$, respectively. Spike2 4.11 software (Cambridge Electronic Design) was used for off-line analyses.
Field potentials recorded at the vibrissal motor cortex and collected for analysis were obtained averaging up to 60 stimulus presentations (CS presentations, and contralateral whisker-pad or ipsilateral barrel cortex electrical stimuli). To calculate the current source density during the presentation of somatosensoryrelated stimuli, the one-dimensional approach described by Freeman and Nicholson (1975) was used, assuming that the extracellular space of the vibrissal motor cortex was isotropic, homogeneous, and with an approximate resistivity of 300 $\Omega \times \mathrm{cm}$ (Demirci et al. 1997; Varona et al. 2000). The occurrence of spontaneous oscillations in the electrical activity of the vibrissal motor cortex, with an event-related-like morphology, was detected using a Spike2 pattern-recognition routine.

The multi-unit activity recorded in chronic mice was extracted from vibrissal motor cortex ECG recordings using a highpass digital filter (500 Hz cut-off frequency) and the Spike2 4.11 spike-sorting routine (Cambridge Electronic Design), which utilizes user-defined amplitude, duration, and waveform criteria to isolate individual spikes from multi-unit recordings. The unit activity recorded in acute mice was differentiated from ECG signals recorded from the vibrissal motor cortex, using a level window on a high-pass filter (500 Hz cut-off frequency). In both cases, and in order to accept a distinguished unit as a pyramidal neuron, its basal firing frequency had to be $<10$ spikes per second, and the total duration of the spike had to be $>3 \mathrm{msec}$.

In order to determine the percentage of CRs per session, the EMG activity recorded from the whisker-pad intrinsic musculature during each trial was evaluated. To be considered a CR, each increase in EMG activity had to fulfill the following criteria: (1) its onset had to be between $40 \mathrm{msec}$ after the CS and the onset of the US; (2) its amplitude had to be greater than the mean plus three standard deviations of the baseline activity (100 msec before CS onset); and (3) its duration had to exceed $10 \mathrm{msec}$. Responses starting during the first $40 \mathrm{msec}$ after CS onset were considered "alpha responses" and were not included in the quantitative analysis of collected data. The conditioning criterion was defined as the performance of CRs in at least $60 \%$ of the trials of a complete session.

In chronic experiments, the EMG activity recorded from whisker-pad intrinsic muscles was rectified off-line and then averaged using as trigger either CS presentation, pyramidal neuron spikes, or event-related-like vibrissal motor cortex spontaneous oscillations. In order to study the evolution of EMG recordings across conditioning, and to explore its relationship with the vibrissal motor cortex CS-evoked field potentials, their amplitude and the area-under-the-curve modulus were normalized, expressing them as relative percent increments with respect to baseline records (100 msec epoch prior to stimulus presentation). To explore this relationship further, both averaged signals were divided into eight epochs of $30 \mathrm{msec}$. EMG epochs were delayed 10 msec with respect to the CS-evoked field potentials (see Fig. 2A,B). Both epoch duration and EMG-to-ECG delay were based on delay values collected from primary motor cortex stimulation experiments (see Fig. 3A,B).

Unless otherwise indicated, mean values are followed by their standard deviation (S.D.), and were computed from a minimum of 10 measurements. Across-training differences between conditioned and pseudoconditioned groups, and relationships between field potentials or unit activity recorded in the vibrissal motor cortex and whisker-pad muscular activities, were evaluated using either repeated measures analysis of variance (ANOVA) or correlation modules of SigmaStat 3.01 (SPSS Inc.). A probability level of $P \leq 0.05$ was used as an index of statistical significance.

\section{Acknowledgments}

This work was supported by BFU2005-01024, JA/CVI-122, and JA/CTS-168 grants from Spain. J.T. was a doctoral student and A.M. a postdoctoral fellow of the Spanish Fundación Carolina. We thank Mr. Roger Churchill for help in the editing of the manuscript.

\section{Learning \& Memory}




\section{References}

Ahrens, K.F. and Kleinfeld, D. 2004. Current flow in vibrissa motor cortex can phase-lock with exploratory rhythmic whisking in rat. $J$. Neurophysiol. 92: 1700-1707.

Baranyi, A., Szente, M.B., and Woody, C.D. 1991. Properties of associative long-lasting potentiation induced by cellular conditioning in the motor cortex of conscious cats. Neuroscience 42: 321-334.

Demirci, M., Ayata, C., Dalkara, T., Erdemli, G., and Onur, R. 1997. Monitoring cellular edema at single-neuron level by electrical resistance measurements. J. Neurosci. Methods 72: 175-181.

Deschênes, M., Veinante, P., and Zhang, Z.W. 1998. The organization of corticothalamic projections: Reciprocity versus parity. Brain Res. Brain Res. Rev. 28: 286-308.

Diamond, M.E. 1995. Somatosensory thalamus of the rat. In Cerebral cortex, Vol. 11. The barrel cortex of rodents (eds. E.G. Jones and I.T. Diamond), pp.189-219. Plenum Press, New York.

Donoghue, J.P. and Parham, C. 1983. The afferent connections of the lateral agranular field of the rat motor cortex. J. Comp. Neurol. 217: 390-404.

Donoghue, J.P., Kerman, K.L., and Ebner, F.F. 1979. Evidence of two organizational plans within the somatic sensory-motor cortex of the rat. J. Comp. Neurol. 183: 647-664.

Donoghue, J.P., Suner, S., and Sanes, J.N. 1990. Dynamic organization of primary motor cortex output to target muscles in adult rats. II. Rapid reorganization following motor nerve lesions. Exp. Brain Res. 79: 492-503.

Franchi, G. 2001. Persistence of vibrissal motor representation following vibrissal pad deafferentation in adult rats. Exp. Brain Res. 137: $180-189$.

Franchi, G. 2002. Time course of motor cortex reorganization following botulinum toxin injection into the vibrissal pad of the adult rat. Eur. J. Neurosci. 16: 1333-1348.

Freeman, J.A. and Nicholson, C. 1975. Experimental optimization of current source-density technique for anuran cerebellum. $J$. Neurophysiol. 38: 369-382.

Frey, U., Schollmeier, K., Reymann, K.G., and Seidenbecher, T. 1995. Asymptotic hippocampal long-term potentiation in rats does not preclude additional potentiation at later phases. Neuroscience 67: 799-807.

Friedman, W.A., Jones, L.M., Cramer, N.P., Kwegyir-Afful, E.E., Zeigler, H.P., and Keller, A. 2006. Anticipatory activity of motor cortex in relation to rhythmic whisking. J. Neurophysiol. 95: 1274-1277.

Galvez, R., Weiss, C., Weible, A.P., and Disterhoft, J.F. 2006. Vibrissa-signaled eyeblink conditioning induces somatosensory cortical plasticity. J. Neurosci. 26: 6062-6068.

Grinevich, V., Brecht, M., and Osten, P. 2005. Monosynaptic pathway from rat vibrissa motor cortex to facial motor neurons revealed by lentivirus-based axonal tracing. J. Neurosci. 25: 8250-8258.

Hayashi, S., Shimura, K., and Kasai, T. 2005. Rapid plastic changes of human primary motor cortex with repetitive motor practice and transcranial magnetic stimulation. Percept. Mot. Skills 101: 575-586.

Hess, G. 2003. Synaptic plasticity of local connections in rat motor cortex. Acta Neurobiol. Exp. (Warsz.) 63: 271-276.
Hess, G. and Donoghue, J.P. 1994. Long-term potentiation of horizontal connections provides a mechanism to reorganize cortical motor maps. J. Neurophysiol. 71: 2543-2547.

Hess, G., Aizenman, C.D., and Donoghue, J.P. 1996. Conditions for the induction of long-term potentiation in layer II/III horizontal connections of the rat motor cortex. J. Neurophysiol. 75: 1765-1778.

Huntley, G.W. 1997. Correlation between patterns of horizontal connectivity and the extent of short-term representational plasticity in rat motor cortex. Cereb. Cortex 7: 143-156.

Izraeli, R. and Porter, L.L. 1995. Vibrissal motor cortex in the rat: Connections with the barrel field. Exp. Brain Res. 104: 41-54.

Jacobs, K.M. and Donoghue, J.P. 1991. Reshaping the cortical motor map by unmasking latent intracortical connections. Science 251: 944-947.

Keller, A., Weintraub, N.D., and Miyashita, E. 1996. Tactile experience determines the organization of movement representations in rat motor cortex. Neuroreport 7: 2373-2378.

Krakauer, J.W. and Shadmehr, R. 2006. Consolidation of motor memory. Trends Neurosci. 29: 58-64.

Miyashita, E., Asanuma, H., and Keller, A. 1994. Input-output organization of the rat vibrissal motor cortex. Exp. Brain Res. 99: 223-232.

Mountcastle, V.B. 1997. The columnar organization of the neocortex. Brain 120: 701-722.

Nudo, R.J. and Milliken, G.W. 1996. Reorganization of movement representations in primary motor cortex following focal ischemic infarcts in adult squirrel monkeys. J. Neurophysiol. 75: 2144-2149.

Paxinos, G. and Franklin, K.B.J. 2001. The mouse brain in stereotaxic coordinates. Academic Press, London, UK.

Sanes, J.N. 2003. Neocortical mechanisms in motor learning. Curr. Opin. Neurobiol. 13: 225-231.

Sanes, J.N. and Donoghue, J.P. 2000. Plasticity and primary motor cortex. Annu. Rev. Neurosci. 23: 393-415.

Sanes, J.N., Wang, J., and Donoghue, J.P. 1992. Immediate and delayed changes of rat motor cortical output representation with new forelimb configurations. Cereb. Cortex 2: 141-152.

Siucinska, E. and Kossut, M. 2004. Experience-dependent changes in cortical whisker representation in the adult mouse: A 2-deoxyglucose study. Neuroscience 127: 961-971.

Thomson, A.M. and Bannister, A.P. 2003. Interlaminar connections in the neocortex. Cereb. Cortex 13: 5-14.

Toldi, J., Laskawi, R., Landgrebe, M., and Wolff, J.R. 1996. Biphasic reorganization of somatotopy in the primary motor cortex follows facial nerve lesions in adult rats. Neurosci. Lett. 203: 179-182.

Troncoso, J., Múnera, A., and Delgado-García, J.M. 2004. Classical conditioning of eyelid and mystacial vibrissal responses in conscious mice. Learn. Mem. 11: 724-726.

Varona, P., Ibarz, J.M., López-Aguado, L., and Herreras, O. 2000. Macroscopic and subcellular factors shaping population spikes. $J$. Neurophysiol. 83: 2192-2208.

Received June 7, 2006; accepted in revised form November 22, 2006. 


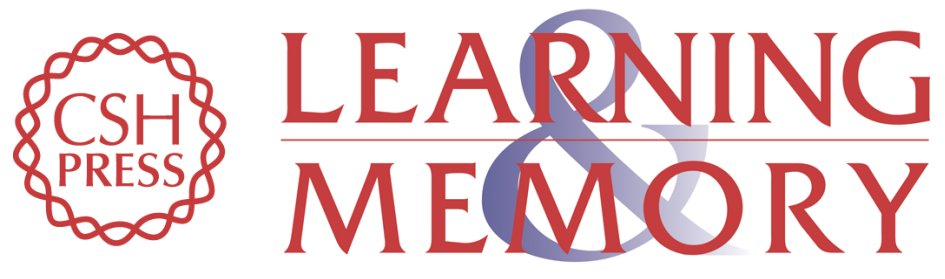

\section{Learning-dependent potentiation in the vibrissal motor cortex is closely related to the acquisition of conditioned whisker responses in behaving mice}

Julieta Troncoso, Alejandro Múnera and José María Delgado-García

Learn. Mem. 2007, 14:

Access the most recent version at doi:10.1101//m.341807

References This article cites 34 articles, 4 of which can be accessed free at: http://learnmem.cshlp.org/content/14/1-2/84.full.html\#ref-list-1

License

Email Alerting

Receive free email alerts when new articles cite this article - sign up in the box at the Service top right corner of the article or click here. 